\title{
Race, Metaphor, and Myth in Academic Medicine
}

\author{
Nicolás E. Barceló ${ }^{1}$ (D) Sonya Shadravan ${ }^{2}$
}

Received: 15 February 2020 / Accepted: 2 October 2020 / Published online: 21 October 2020

(C) Academic Psychiatry 2020

"The quality of light by which we scrutinize our lives has direct bearing upon the product which we live, and upon the changes which we hope to bring about through those lives."

—Audre Lorde [1]

We are currently living in an unprecedented historical time during which efforts to unmask injustice and demand systemic change are far-reaching and unbridled. Corporations and service institutions alike are struggling to conjure up slogans and marketing strategies to align with the righteous demands of protestors and citizens, often times skipping the critical steps of institutional reflection and fundamental paradigm shifting. As advocates dedicated to promoting racial justice in our residency program and medical center, we have witnessed parallel processes in academic medicine - an expressed wish to market diversity without the institutional accountability requisite to promote justice and radical transformation.

Throughout our experience as practitioners of equity initiatives in academic medicine, we have encountered many widely utilized metaphors in the Diversity and Inclusion frameworks provided to us - variably by our own institutions, professional organizations, published in our most prominent journals, and by academic medicine's flagship, the Association of American Medical Colleges (AAMC). While these tools are intended to advance principles of unity and equity, we have been unsettled by the subtle but nevertheless powerful racial mythology they often advance. Many of these frameworks which remain in common use carry an undercurrent which perpetuates racial hierarchies, cultural determinism, and white hegemony. It is our experience that as they

Nicolás E. Barceló

nbarcelo@mednet.ucla.edu

1 University of California, Los Angeles, Los Angeles, CA, USA

2 Office of Diversion and Reentry, Los Angeles, CA, USA are currently defined, generally understood, and commonly practiced, many "diversity" frameworks used throughout academic medicine and in the clinical learning environment fail to adequately illuminate mechanisms of injustice. Through use of imagery and rhetorical devices that contain racialized myths, these frameworks often propagate the same unjust paradigms they are intended to address. These metaphors are ubiquitous throughout medical education, and their eradication is a matter of joint accountability among all physicians. As psychiatrists, however, we call on our field to catalyze this work, for we believe that our training offers a unique preparedness to consider how cognitive devices perpetuate oppression.

Critical race theory (CRT) asserts that racism is ubiquitous, operating through unspoken assumptions, beliefs, and systems. CRT therefore challenges the organizing principles behind these ideas and racialized power relations not only to understand inequity but to eliminate it $[2,3]$. In this commentary, we strive to advance the quality of the light by which we scrutinize our collective work by applying a CRT framework in drawing attention to the harmful racialized mythology latent in three well-circulated diversity concepts. These myths pertain to the etiology of racial oppression, the scarcity of marginalized applicants in medicine, and the effectiveness of a diversity operating system. We offer counter-narratives and alternative imagery in order to challenge the ongoing rote adoption of harmful frameworks in our field. While some of the images we discuss have been previously critiqued, they are nevertheless continually relied upon in the dominant discourse, thereby demanding continued attention. Additionally, we offer new perspectives in critique of previously unchallenged norms embedded within Diversity and Inclusion frameworks. These contributions reflect our understanding that tools for deconstructing racism are necessarily dynamic and ever-improving. We hope to contribute to a collective CRT-inspired praxis of increasing our powers of perception and critical reflection within the medical community, so as to improve the nuance, honesty, and power of the just systems we are able to create. 


\section{The Etiology of Racial Oppression and the Myth of Inherent Shortness}

We begin with an image that has become pervasive in equityminded spaces, which we will call the "baseball watchers." [4] The image contains three parts and begins with a scene depicting three individuals of different heights, trying to watch a baseball game from behind a fence. The image progresses in two subsequent panes to contrast equality-based interventions (equal treatment) versus equity-based interventions (ensuring equal outcomes). For equality, the image depicts each individual standing on one equally sized box attempting to look over the fence - it is clear in this image that the tallest person never required a box (they could already see) and that for the smallest person, one box would not be enough (as they still cannot see). Alternatively, for equity, the same three individuals are given according to their need - the tall person does not need a box, the medium-height person has one box, and the short person has two boxes. In this case, all three individuals can see. Further variations of the image posit replacing the wood fence with a chain-link, similarly striving to allow each person, regardless of height, to watch the game [5].

We note that while the image depicts individuals, the discussion accompanying this image is invariably about population groups and population-level disparity, frequently focused on race and ethnicity. With this in mind, although it is important to challenge one-size fits all interventions, this image does not interrogate the premise that they "just are" different heights. If we believe the goal for all groups is to be able to watch the game, and if we accept the suggestion that differences in ability to watch are a reflection of height, the image suggests that some groups are innately or biologically determined to be less apt to succeed, propagating a fallacy of meritocracy. In turn, those deemed short are portrayed as responsible for their own short-comings (inferiority), and the better outcomes experienced by the privileged group are attributable to their naturally "taller" stature (read superiority).

Grappling with the assumptions that frame a viewer's conception or acceptance of the initial scene is important because it defines how we understand the problem. From that point of departure, we then define what our intervention might be. Based on an understanding that "we" are tall, and "they" are short, it follows that the generous action would be to provide boxes to the short people or to make the fence transparent, as has been depicted.

From the experience of marginalized groups [6], we cannot accept the unspoken premise as an accurate reflection of contemporary inequity - that the disparities experienced by marginalized communities of color are attributable to intrinsic inferiority. If we truly grasp that unlike early pseudoscientific presumption about racial hierarchy, race is in fact a social construct, we understand that differences in outcomes or health between groups should be attributed to differences in how people are differentially treated vis-a-vis structural oppression or privilege [2]. In other words, constructed and perpetuated social position. Rather than depict groups as inherently short, what would be more appropriate to unveil, the structural forces that distort how groups are socially appraised, would be an image depicting three individuals, born and having grown to the same height, one forced into a ditch, one chained to the ground, and one standing, already on a block of privilege [7] (Fig. 1). This perspective helps to redirect how we think about difference and subsequently informs the quality and accountability of our interventions.

The myth of racial hierarchy embedded within the baseball watchers may be difficult to detect because well-meaning the intention of the image is to focus on interventions. Nevertheless, it perpetuates bias, which, by definition, distorts our ability to see things as they are - causing some to believe others are short, not realizing they stand on a metaphorical box. Viewing this image from the perspective of marginalized groups alternatively invites us to consider the double failing, (1) a lack of acknowledgment of the structural processes that rob groups of their height and (2) the disingenuousness of offering boxes to people standing in ditches.

\section{Medical Saviorism and the Myth of "URM Scarcity"}

Equity, diversity and inclusion (EDI) recruitment frameworks in medicine are replete with assumptions of the scarcity of "qualified" applicants of color. In conversations related to medical education and the healthcare workforce, marginalized groups are frequently identified by the umbrella term "under-represented in medicine" (URM). Despite its true definition, it is commonplace to encounter interpretations of URM as "under-represented minorities" [8]. This misuse has several problems: first, it conflates demographic "minority" (i.e., racial groups not represented in the city at large) with racialized marginalization (i.e., racial groups present in the city, but subjugated and excluded from medicine), where the latter better accounts for representation in medicine which is below populationbased trends, persistent even despite demographic shifts. Second, emphasis on "historic" under-representation shifts focus away from contemporary practices that drive modern segregation in medical education-how under-represented groups remain under-represented even despite calls for diversity. Finally, among other concerns, the naming of URM groups turns attention away from non-URM groups. Rather than presuming the normalcy of white representation in medicine, for example, these groups might be better named "historically over-represented in medicine" (ORM). Finally, emphasis on representation alone may distract attention away from other processes of marginalizationincluding the disparity between levels of representation 
Fig. 1 Portrayed are three people, of equal stature, experiencing external forces that distort how tall they appear. [7]. This image reveals biased foundational beliefs about innate differences in value or merit that often undermine the success of equitybased interventions. Copyright 2020 by Nicolás E. Barceló and Sonya Shadravan (Artist: Aria Ghalili). Reprinted with their permission

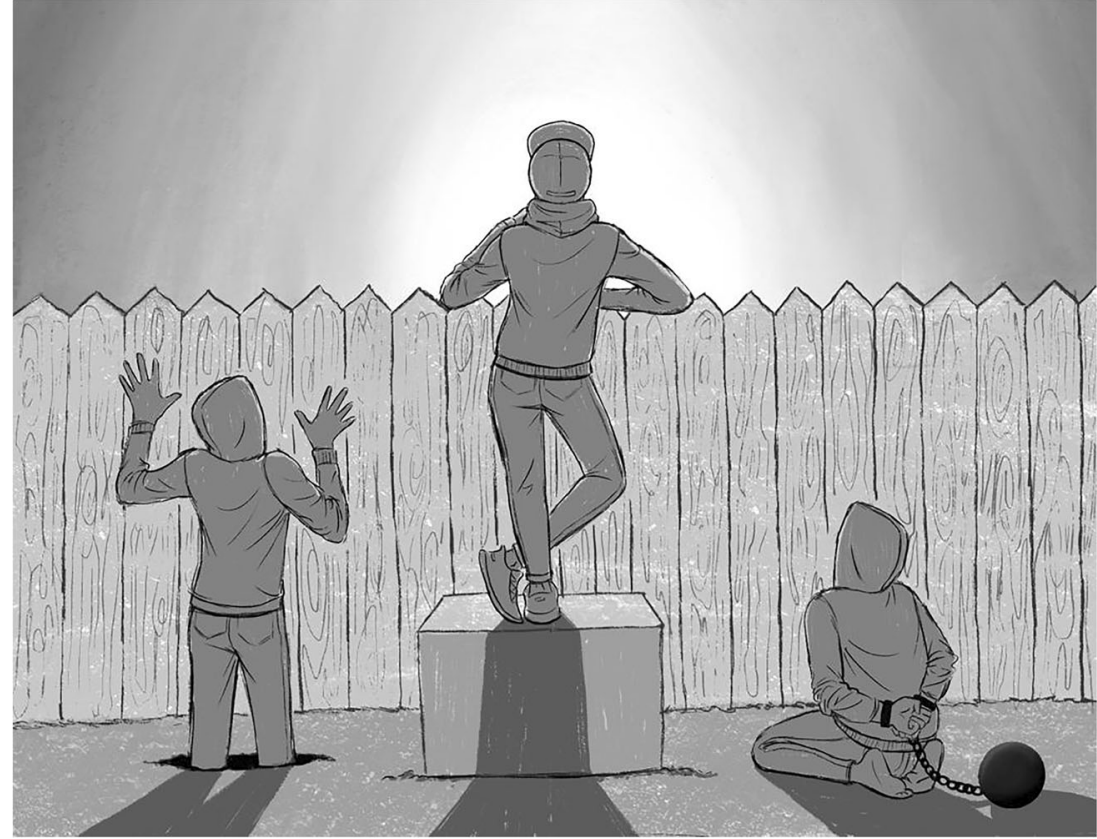

for women and Asian physicians relative to their occupancy in positions of leadership [9-13].

As is the case with the "baseball watchers" image, contemporary recruitment efforts propagate conceptual mythology that limit their viability to succeed. Within GME spaces, there is perhaps no better example of this cognitive dissonance than the continued use of USMLE STEP1 as a primary metric for entrance to residency. Evidence shows a statistical significance between high STEP1 scores and white male identity [14-16]. These outcomes echo trends in the MCAT-where there are known ties between social position (tracking racial marginalization) and exam score [17]. Further, no evidence exists to demonstrate a predictive association between STEP1 and future physician clinical contribution [18]. Not only therefore does this continued use of STEP1 unduly privilege white male applicants, this practice comes at the expense of communities of color - their access to racially and linguistically concordant providers $[19,20]$ and potential for improved health outcomes [21, 22]. In each of these ways, despite calls to "diversify" the workforce, emphasis on STEP1 manufactures a state of scarcity that reflects neither the true number of applicants of color available nor the clinical contribution they may provide. Equally problematic, wide-spread practice of using STEP 1 as a primary determinant in selection normalizes its effect, thereby giving the impression that recruitment outcomes are incidental (conveniently attributed to demographic minority status) and provides a shield of innocence in defending the processes that generate scarcity.

One response to the perceived scarcity of marginalized applicants has been to grant consideration to "distance traveled" in recruitment efforts. This shift purports to take into consideration the "starting point" of an applicant and thereby contextualize the significance of their achievements (according to whether they grew up in an underserved community or whether they were the first in their family to graduate high school or college, for example). We believe these are important considerations in advocating for marginalized groups. At the same time, however, we reflect on instances where we have heard statements like: "they probably would have had better test scores, but they had to work and couldn't study as much." Without refuting the likely truth of this statement, we observe the assumptions and implications - while making an allowance for lower test scores, the practice nonetheless utilizes test scores, a measure known to create bias as the continued reference metric for merit. Further, it reinforces the idea that high test scores are the desirable outcome and centralizes the lived experience of applicants whose privileged social position (allowing for dedicated time to study, additional tutoring and study tools, etc.) leads them to high test scores without needing points for "distance traveled." According to this perspective and practice, points for distance traveled are the metaphorical equivalent to giving boxes to people believed to be short.

Academic medicine perpetuates the myth that racially marginalized, qualified candidates are inherently "scarce" and in need of "recruitment," all the while participating directly in manufacturing the conditions that make our field inhospitable to marginalized candidates [23, 24]. With this understanding, how can academic medicine genuinely take credit for "recruiting" marginalized candidates through "calls for diversity" and "diversity second look days?" This is akin to the CEO of a multinational corporation responsible for climate change and deforestation seeking praise for their initiatives in tree planting. 
Mythology around race and racial scarcity in recruitment obscures the reality we are facing and perpetuates harmful beliefs about racial difference and merit. Returning to the metaphor of the baseball watchers, there will ultimately be applicants from marginalized groups who appear "qualified" without recognition of distance traveled. If standing in a ditch and nonetheless appearing "normal" height, it follows that this applicant may actually be $9 \mathrm{ft}$ tall! A focus limited to the experience of "URM" applicants would characterize this applicant as being qualified and fail to register the true magnitude of their accomplishment. All the while this focus would simultaneously overlook the ways in which the "height" of other applicants is therefore, in fact, only par for the course they have traveled.

\section{Diversity in the Workforce: the Myth of an Advancing Diversity Operating System}

Throughout history, the creation of race, based on distinct and hierarchized categories, has always been preceded by the creation of expanding oppressive systems that require a moral and cognitive justification. In turn, oppression is presumed natural, if some groups are deemed naturally inferior [25]. Further, these systems of subjugation, colonization, and exploitation have often been (and continue to be) fueled by profit motive and the expansion of capitalism.

With this in mind, we consider the "Diversity 3.0" framework presented by the AAMC [26, 27]. While a full analysis is beyond the scope of this commentary, the AAMC offers a view of diversity initiatives and frameworks as subsequent and updating "operating systems," each new release correcting prior flaws and progressing as a result of lessons learned. Briefly, Diversity 1.0 was concerned with undoing legacies of segregation, upholding Civil Rights legislation, and providing justice to individual applicants previously prohibited from entering medicine. This initiatives' ultimate failure was attributed to the widespread belief that "diversity (is) at odds with excellence." Diversity 2.0, therefore, focuses on the benefit of diversity to the larger learning community (read: other white trainees, as opposed to simply achieving justice for trainees of color) and posits that perhaps the educational benefits of diversity will additionally prepare all trainees to better address health inequity (in marginalized patient communities). It is important to note here that diversity is often an imprecise way that leadership refers to the presence or absence of people of color, specifically, rather than as a true depiction of heterogeneity. In Diversity 3.0, diversity itself is re-branded as a valuable "resource" that should be "leveraged" and marketed "to build innovative, high-performing organizations" [26]. According to this definition, neither the professional opportunity of applicants of color (Diversity 1.0) nor the health of marginalized communities (Diversity 2.0) are the primary intended beneficiaries. Instead, we see the medical enterprise, and its advertised "excellence," as the driving motive. This is referred to as the business argument for diversity. It should be noted that these concepts are widespread and perpetuated even by individuals not directly familiar with the "diversity operating system" framework but who have, rather, tuned in to the discourse du jour. While these approaches are often guided by broader trends, case law, and educational-legal limitations, these broader limitations can also be over-stated by institutional leaders as an alibi for inaction, without grappling with the true meaning of the law, or further, without engaging in physician advocacy when the laws are at odds with racial justice.

In light of the suggestion that Diversity 1.0, 2.0, and 3.0 represent advances in the "operating systems" guiding diversity work, how do we make sense of stagnant or declining levels of marginalized communities represented in medical training? [28-30] Further, relative to the concrete and measurable outcomes at the center of Diversity 1.0 and 2.0 , outcomes that focus the intended benefit directly to trainees and communities of color, how does one reconcile the need to make medical centers excellent when those medical centers have believed themselves to be "excellent" all along? If a medical center with no faculty of color brings in one, two, three highly accomplished faculty of color, they might then satisfy their arbitrary expectations of diversity and excellence under Diversity 3.0, with no accountability for the experience of those faculty [31, 32]. Those faculty, fulfilling unspoken quotas under this framework, may, instead remain the token few, featured on websites and brochures, who can be pointed to when new concerns for lack of diversity arise [33].

Consider instead, when Diversity 1.0 was deemed incompatible with the needs of academic medicine because "diversity was at odds with excellence." Rather than skipping to another framework, we had the opportunity to instead challenge, deconstruct, and redefine what we meant by excellence, understanding that any system which perpetuates structural racism cannot, in fact, be excellent. We had the opportunity to recognize the concept of "diversity being at odds with excellence" as a symptom of racism, a virus affecting the operating system, and we could have refused to proceed to further iterations of the operating system until structural racism; this virus was addressed. Instead of concerning itself with the difficult work of honestly tackling structural racism so as to have an effective system to counter it, the operating system redefined diversity and changed the goal of the system.

In this light, we bring attention to the recent decision to revise USMLE STEP1 to a pass/fail system [34]. While we are encouraged by this transition, our discussion of the Diversity operating system focuses attention on how processes may evolve without resolving root issues. Returning again to the "baseball watchers"-STEP1 could be considered the fence, and group-level disparity in test outcomes the perceived 
height of watchers. To remove the fence (or to change its height, make it see-through, etc.) does not necessarily change erroneous assumptions of the watchers "being short." In this sense, the use of STEP1 is testament to implicit institutional values that, without being addressed directly, will invariably present in new forms. For example, because underlying myths have not been corrected, we are not surprised by the alreadypresent objection from groups for whom STEP 1 has provided advantage - for those who believe in the "myth of shortness" (and their own tall stature). Anger is a predictable response when height is made irrelevant.

In sum, Diversity 3.0 attempts to offer a win-win framework and provides even marginalized groups some validation- "yes, you do have something to contribute, you are capable of working in different and creative ways." Problematically, however, is that contribution is made contingent on the benefit to the medical center and its marketing. Ultimately, if racism was born out of Capitalism [25], we cannot anticipate the "business argument" to result in racial equity. If oppression thrives in contexts that mask its presence and silence those who suffer, frameworks that do the same cannot generate healing and true transformation.

\section{Conclusion}

While metaphors can serve as powerful tools for shedding light on inequity and imagining solutions in healthcare and beyond, when left unexamined, they can conversely perpetuate harmful presumptions. In this article, we have highlighted three prevalent examples of detrimental racial myths inherent in widely utilized EDI tools within academic medicine. Some of the myths we have explored include that of inherent racial difference (failing to consider structural racism and subjugation), the inherent scarcity of qualified medical applicants of color (failing to consider how scarcity is manufactured), and the myth of an ever-advancing diversity operating system. These fallacies, which are foundational to racist ideology, cannot remain at the center of tools purporting to promote justice and equity. Our hope, instead, is to nurture a collective commitment to honestly addressing the powerful and persistent forces of structural racism and developing accountability for the impact of the narratives we tell and the metaphors we create.

Acknowledgments To our communities who remind us who we are. Elements included in this commentary were first presented during a workshop at the 2019 American Psychiatric Association Annual Meeting (San Francisco, CA): "Creating a Culture of Diversity and Inclusion in the Clinical Learning Environment"; co-panelists included DeJong S, Stewart A, Rorbaugh R, Cama S, Levounis P, Ton H, Adams A, and Sudak D. Original art included in this commentary was developed by the authors and first presented by both authors in poster form at the February 28, 2020, Minority Health Conference at UCLA (Los Angeles, CA): "Stop Drawing us Short: Limitations and Possibilities in Graphic Representations of Power and Privilege."
Funding N.B. is supported the by the APA SAMHSA Minority Fellowship, Grant 1H79SM080388-01.

\section{References}

1. Lourde A. Poetry is not a luxury. Sister Outs. Berkeley: Crossing Press; 1984.

2. Ford CL, Airhihenbuwa CO. The public health critical race methodology: praxis for antiracism research. Soc Sci Med. 2010;71:1390-8.

3. Delgado R, Stefancic J. Critical race theory: an introduction. 3rd ed. New York: New York University Press; 2017.

4. Interaction Institute for Social Change | Artist: Angus Mcguire. Illustrating Equality Vs Equity [Internet]. 2016 [cited 2020 Apr 24]. Available from: https://interactioninstitute.org/illustratingequalityvs-equity/

5. Froehle C. The evolution of an accidental meme [Internet]. Medium. 2016 [cited 2020 Aug 19]. p. 1-41. Available from: https://medium.com/@CRA1G/the-evolution-of-an-accidentalmeme-ddc4e139e0e4. Accessed 24 Apr 2020

6. Matsuda MJ. Looking to the bottom: critical legal studies and reparations. Harvard Civil Rights-Civil Lib Law Review. 1987;323: 323-99.

7. Barcelo NE, Shadravan SM. Stop drawing us short: limitations and possibilities in graphic representations of power and privilege. (Artist: Aria Ghalili). Los Angeles, CA. 28 February 2020

8. Page KR, Castillo-Page L, Poll-Hunter N, Garrison G, Wright SM. Assessing the evolving definition of underrepresented minority and its application in academic medicine. Acad Med. 2013;88:67-72.

9. Johnson S, Sy T. Why aren't there more Asian Americans in leadership positions? [Internet]. Harvard Bus Rev Digit Artic. 2016 [cited 2020 Feb 13]. p. 2-5. Available from: https://hbr.org/2016/ 12/why-arent-there-more-asian-americans-in-leadership-positions. Accessed 13 Feb 2020

10. Xierali IM, Fair MA, Nivet MA. Faculty diversity in U.S. medical schools: progress and gaps coexist. AAMC Analysis in Brief [Internet]. 2016;16:2. Report available from: https://www.aamc. org/download/474172/data/december2016facultydiversityinu.s. medicalschoolsprogressandgaps.pdf. Accessed 13 Feb 2020

11. Nakayama DK. Asian Americans in leadership positions in academic surgery. Ann Surg. 2012;255:583-8.

12. Larson AR, Kan CK, Silver JK. Representation of women physician deans in U.S. Medical Schools. J Women's Health. 2019;28: 600-5.

13. Carr PL, Raj A, Kaplan SE, Terrin N, Breeze JL, Freund KM. Gender differences in academic medicine: retention, rank, and leadership comparisons from the national faculty survey. Acad Med. 2018;93:1694-9.

14. Dawson B, Iwamoto CK, Ross LP, Nungester RJ, Swanson DB, Volle RL. Performance on the National Board of Medical Examiners part I examination by men and women of different race and ethnicity. JAMA. 1994;272:674-9.

15. Veloski JJ, Callahan CA, Xu G, Hojat M, Nash DB. Prediction of students' performances on licensing examinations using age, race, sex, undergraduate GPAs, and MCAT scores. Acad Med. 2000;75: S28-30

16. Boatright D, Ross D, O’Connor P, Moore E, Nunez-Smith M. Racial disparities in medical student membership in the Alpha Omega Alpha Honor Society. JAMA Intern Med. 2017;177:659-65.

17. Girotti JA, Chanatry JA, Clinchot DM, McClure SC, Sein AS, Walker IW, et al. Investigating group differences in examinees' preparation for and performance on the new MCAT exam: Academic Medicine; 2019. 
18. Moynahan KF. The current use of United States medical licensing examination step 1 scores: holistic admissions and student wellbeing are in the balance. Acad Med. 2018;93:963-5.

19. Komaromy M, Grumbach K, Drake MI, Vranizan K, Lurie N, Keane D, et al. The role of black and Hispanic physicians in providing health care for underserved populations. N Engl J Med. 1996;334:1305-10.

20. Walker KO, Moreno G, Grumbach K. The association among specialty, race, ethnicity, and practice location among California physicians in diverse specialties. J Natl Med Assoc [Internet]. Elsevier Masson SAS; 2012;104:46-52. Available from: https://doi.org/10. 1016/S0027-9684(15)30126-7

21. Parker MM, Fernández A, Moffet HH, Grant RW, Torreblanca A, Karter AJ. Association of patient-physician language concordance and glycemic control for limited-english proficiency latinos with type 2 diabetes. JAMA Intern Med. 2017;177:380-7.

22. Traylor AH, Schmittdiel JA, Uratsu CS, Mangione CM, Subramanian U. Adherence to cardiovascular disease medications: does patient-provider race/ethnicity and language concordance matter? J Gen Intern Med. 2010;25:1172-7.

23. Mensah MO. Making all lives matter in medicine from the inside out. JAMA Intern Med. 2017;177:1413-4.

24. Mensah MO. Majority taxes - toward antiracist allyship in medicine. N Engl J Med. 2020;383:E23.

25. Kendi IX. How to be an antiracist. Random House LLC: New York; 2019.

26. Nivet MA. Diversity 3.0: a necessary systems upgrade. Acad Med. 2011;86:1487-9.

27. Nivet MA. A Diversity 3.0 Update: Are we moving the needle enough? Acad Med. 2015;90:1591-3.
28. Iglehart JK. Diversity dynamics - challenges to a representative U.S. medical workforce. N Engl J Med. 2014;371:1471-4.

29. Talamantes E, Henderson M, Fancher T, Mullan F. Closing the gap - making medical school admissions more equitable. N Engl J Med. 2019;380:803-5.

30. Hsu P, Balderas-Medina Anaya Y, Hayes Bautista D. 5 centuries to reach parity: an analysis of how long it will take to address California's Latino physician shortage. UCLA Lat Policy Polit Initiat [Internet]. 2018; Available from: https://atino.ucla.edu/wpcontent/uploads/2018/10/5-Centuries-to-Reach-Parity-UCLALPPI.pdf. Accessed 13 Feb 2020

31. Shim RS. Structural racism is why I'm leaving organized psychiatry [Internet]. STAT News. 2020 [cited 2020 Aug 19]. p. 1-7. Available from: https://www.statnews.com/2020/07/01/structuralracism-is-why-im-leaving-organized-psychiatry/. Accessed 19 Aug 2020

32. Cyrus K. Why I gave up my dream of leading diversity efforts in medicine [Internet]. AAMC News. 2020 [cited 2020 Aug 19]. p. 1-3. Available from: https://www.aamc.org/news-insights/why-i-gave-mydream-leading-diversity-efforts-medicine. Accessed 19 Aug 2020

33. Cyrus KD. Medical education and the minority tax. JAMA. 2017;317:1833-4.

34. United States Medical Licensing Examination. Change To Pass/Fail Score Reporting for Step 1 [Internet]. InCUS - Invit. Conf. USMLE Scoring. 2020 [cited 2020 Feb 13]. Available from: https://www.usmle.org/inCus/\#decision. Accessed 13 Feb 2020

Publisher's Note Springer Nature remains neutral with regard to jurisdictional claims in published maps and institutional affiliations. 